\title{
Clinical Outcome Following Treatment Of Pertrochanteric Fractures With Dynamic Hip Screw In A Nigerian Rehabilitation Hospital
}

\author{
Mue D.D ${ }^{1}$, Salihu M.N ${ }^{2}$, Awonusi F.O ${ }^{2}$ \\ ${ }^{1}$ (Department of surgery, Benue State University Makurdi- Nigeria) \\ ${ }_{2}^{2}$ (Department of clinical services, National orthopaedic hospital Dala, Kano- Nigeria)
}

\begin{abstract}
Pertrochanteric fracture is a severe and frequent injury with consequent high morbidity and mortality. Dynamic hip screw is an effective treatment modality for stable intertrochanteric hip fractures. It is based on "tension band principle" which allows compression of fracture fragment when the patient bears weight with consequent high rates of union and restoration of hip function to pre injury level. This study determined the epidemiological pattern, care, complications and functional outcome of pertrochanteric fractures following treatment with dynamic hip screw. Retrospective data was obtained over a 5 year period from January, 2007 to December, 2012. All patients with pertrochanteric hip fractures treated with dynamic hip screw were consecutively selected. Data was analysed using SPSS version 21. The total number of patients was

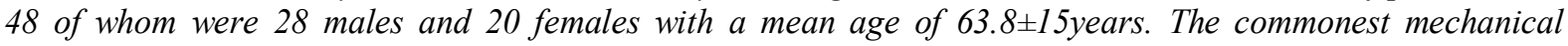
complication encountered was lag screw cut through in 4 (8.3\%) patients. Post-operative hip functional status done according to Postel and Merle d Aubigne scoring system at $4-6$ months postop revealed that majority $(90.0 \%)$ of patients had satisfactory hip function with minimal morbidity. Careful patient selection, proper training of surgeons as well as attention to detail is vital and may minimize failure rates.
\end{abstract}

Keywords: clinical outcome, dynamic hip screw, pertrochanteric fractures.

\section{Introduction}

Trochanteric femoral fractures are, by definition, fractures that involve the proximal region of the femur from the extra capsular part of the femoral neck to the transverse line at the level of the distal end of the lesser trochanter, which defines the inferior limit of the trochanteric region ${ }^{1}$. The incidence of pertrochanteric femoral fractures has increased significantly during recent decades, and this tendency will probably continue in the near future due to the rising age of the population $[1,2]$. Previous retrospective studies by Finsen et al found an increase in the proportion of trochanteric femoral fractures from 32\% in 1972-1984 to 68\% in 1997-1998[2, 3].

Treatment of Trochanteric femoral fractures poses a challenge to the orthopaedic the surgeon especially in the elderly because of higher bone fragility due to osteoporosis and medical co-morbidities which complicates treatment. These fractures predominantly occur in the population over 60 years of age and are 3-4 times more frequent in women than in men [4]. Although they could unite with conservative treatment but with high rate of mal union associated with coxa vara deformity and shortening, therefore, stable reduction and rigid internal fixation is the method of choice in the treatment of trochanteric femoral fractures [5] as this enables early mobilization and restoration of function which could be life-saving as complications of prolonged immobilization may be fatal in the elderly [5].

Although many devices can achieve rigid fixation, the dynamic hip screw (DHS) is currently the most frequently used device for intertrochanteric hip fracture [6-8] . The DHS is based on tension band principle and allow the screw to slide within the barrel to enable compression of the fracture when the patient begins to bear weight. The principle only works in the presence of intact posteromedial wall in the region of the lesser trochanter and so cannot be successful in unstable patterns such as reverse oblique fractures, fractures with large posteromedial fragment and fractures with sub trochanteric extension [7, 8].

The commonest mechanical failure of fixation in using the sliding hip screw system is cut-through of the implant from the femoral head with resultant failure of the system [9-11]. .DHS failure rate has been previously reported as $8 \%-13 \%$ [12] but the rate came down to $6.8 \%$ according to a more recent study [13]. Previous studies have recommended the essential role of adequate reduction of the fracture, as well as central placement of the lag screw on AP and lateral views of the radiographs and suggested that tip apex distance (TAD) is the most important prediction factor for DHS cut through. It is important that the technique of screw placement is precise and should ideally be central in the femoral neck, on both anteroposterior and lateral radiographs. Other predictors of cut through of DHS include fracture pattern, patient's age and presence of osteoporosis $[13,14]$. 
This present retrospective study determined the epidemiological pattern, care, complications and functional outcome of pertrochanteric fractures following treatment with dynamic hip screw.

\section{Materials And Methods}

This retrospective study was conducted at Benue leprosy settlement and Rehabilitation Hospital Mkar, North- Central Nigeria. It consisted of documentary review over a 5 year period from January, 2007 to December, 2012. All patients with pertrochanteric fractures diagnosed clinically and by radiographs that were treated with Dynamic hip screw (DHS) were consecutively selected. Case folders were retrieved from medical records department and data extracted and recorded on a standardized data sheet. Forty eight patients met the criteria for inclusion. Patients with multiple fractures, life threatening medical conditions, non-ambulatory patients and those with incomplete data were excluded from the study. The following variables were studied: demographic data, mechanism of injury, operation time, duration of surgery, estimated blood loss, blood transfusion, duration of hospital stay, wound complications, mortality rate and functional outcome.

Anaesthetic review was obtained for all patients to ascertain fitness for surgery. Appropriate Radiographs of the affected hip were taken to classify the type of fracture. Relevant laboratory investigations, chest radiographs and ECG were done for patients above 40years.

Fixation of fractures with DHS was performed using standard procedure. In the post-operative period, Patients were routinely started on prophylactic antibiotic with $3^{\text {rd }}$ generation cephalosporin which was continued post-operatively for 5 days as per the department's protocol. All patients at moderate to severe risk for DVT were commenced preoperatively on thrombo-embolic prophylaxis with subcutaneous injections of low molecular weight heparin and were continued post-operatively for 14 days when mobilization was established. Rehabilitation was began 48hours after surgery ${ }^{31}$ as the patient lies free in bed and encouraged to carry out gentle isometric exercises to the limit of pain tolerance and graded mobilization was commenced within the first week of surgery. After discharge from hospital the patient was followed at interval of 06 weeks, 03 months, 06 months and 12 months and all complications were documented. The post-operative hip functional status was assessed at about 4-6 months to grade the results according to the hip functional scale of Postel and merle $\mathrm{d}$ Aubigne (PMA) as shown in TABLE $1 \& 2$.

Effect of modifiers like age and gender were controlled through stratification. Data was analysed for frequencies of various variables using the Statistical Program for Social Science (SPSS) version 21.

\section{Results}

The total number of patients was 48 of whom 28(58.3) were males and 20(41.7\%) females with a male to female ratio was of 1.4:1. The age range was 28 to 90 years with a mean age of $64.2 \pm 17$ years as illustrated in Fig. 4. The predominant mechanism of injury was trivial falls in $26(54.2 \%)$ patients followed by vehicular accident in $13(28.1 \%)$ patients, motorcycle accident $7(14.6 \%)$ patients and assault $2(4.2 \%)$ patients as illustrated in figure 2. Majority of the women (57.7\%) were involved in low energy injury- trivial falls while more men $(84.6 \%$ and $85.7 \%)$ were involved on high energy injury - vehicular accident motorcycle accident respectively.

Only 1 patient $(2.1 \%)$ presented within 48 hours of injury while majority $31(66.6 \%)$ of patients presented between 48 hours and 6 weeks of injury. Twenty three patients $(47.9 \%)$ had at least one systemic comorbidity of which $16(33.3 \%)$ were above 60 years. Seventeen $(35.4 \%)$ had hypertension, $3(6.3 \%)$ had Diabetes Mellitus, 1 (2.1\%) had diabetes mellitus and hypertension, $1(2.1 \%)$ had retroviral disease and $1(2.1 \%)$ patient had visual impairment.

Thirty three (68.8\%) patients were operated under spinal anaesthesia and $13(27.1 \%)$ patients underwent surgery under general anaesthesia. Two patients $(4.2 \%)$ were started on spinal anaesthesia but later converted to general anaesthesia due to wearing out of the spinal anaesthesia from prolonged surgery. The mean duration of surgery was $106 \pm 29.4$ minutes with mean estimated blood loss of $330 \pm 120 \mathrm{mls}$ and mean duration of hospital stay of $16.5 \pm 4.1$ days. Majority $44(91.6 \%)$ of the patients walked with some form of external support during the hospitalization period. Early graded mobilization was commenced from parallel bars to Zimmer frame and bilateral axillary crutches.

The commonest complication encountered was surgical site infection in $6(12.5 \%)$ patients followed by cut through of DHS screw in $4(8.3 \%)$ patients; depicted in Fig.3, pressure sore in $2(4.2 \%)$ patient and nonunion in 1(2.1\%) patient as illustrated in Fig. 5. Early post-operative mortality was $1(2.1 \%)$. Follow up time of patients was poor as patients default frequently after a few visits. Seven patients $(14.5 \%)$ were initially lost to follow up and never seen in surgical outpatient clinic after discharge from the hospital. At 6 months follow-up only 38 (79.2) patients were seen. This had dropped to $9(18.8 \%)$ patients at 1year follow up and only $6(18.5 \%)$ patient were seen after 1 year. 
Post-operative hip functional status done according to Postel and Merle d' Aubigne scoring system (TABLE $1 \& 2$ ) at $4-6$ months postop revealed that majority of the surviving patients $(90.0 \%)$ had satisfactory hip function \{Excellent (66.9\%), Very Good (3.3\%) and Good $(20.0 \%)$ \} and $10.0 \%$ patients had fair postoperative hip functional score as shown in Fig. 6.

Table 1: Method of grading functional value of the hip (Postel and Merle D' Aubigne)

\begin{tabular}{|c|c|c|}
\hline PAIN & MOBILITY & ABILITY TO WALK \\
\hline 6. No pain & Flexion of more than $=90^{\circ}$ & Normal \\
\hline 5. Pain is mild and inconstant & Flexion between $80^{\circ}$ and $90^{\circ}$ & Without cane but with slight limp \\
\hline normal activity & Abduction at least $15^{\circ}$ & A lono time with cane short time \\
\hline disappears with rest & $\begin{array}{l}\text { Patient can reach his foot. Flexion } \\
\text { between } 40^{\circ} \text { and } 60^{\circ}\end{array}$ & without cane and with limp \\
\hline $\begin{array}{l}\text { 3. Pain is tolerable with limited } \\
\text { activity }\end{array}$ & & $\begin{array}{l}\text { With one cane, less than one hour; } \\
\text { very difficult without a cane }\end{array}$ \\
\hline $\begin{array}{l}\text { 2. Pain is severe when walking; } \\
\text { prevents any activity }\end{array}$ & Flexion under $40^{\circ}$ & Only with canes \\
\hline 1. Pain is severe even night & $\begin{array}{l}\text { No movement; pain slight } \\
\text { deformity }\end{array}$ & Only with canes \\
\hline 0. Pain is intense and permanent, & $\begin{array}{l}\text { Ankylosis with bad position of } \\
\text { the hip }\end{array}$ & None \\
\hline
\end{tabular}

NO VICIOUS ATTITUDE: Take in account only the bending attitude.

VICIOUS ATTITUDE: Withdraw.

1 Point for $20^{\circ}+$ of bending or irreducible external rotation

2 points for $10^{\circ}$ or + abduction, abduction, irreducible internal rotation

Table 2: Global Assessment of Hip Function (By Merle D’ Aubigne)

\begin{tabular}{|c|c|c|c|c|}
\hline PAIN & MOBILITY & WALKING & TOTAL & APPRECIATION \\
\hline 6 & 6 & 6 & 18 & Excellent \\
\hline 6 & 5 & 6 & 17 & Very good \\
\hline 6 & 6 & 5 & & \\
\hline 5 & 6 & 6 & & \\
\hline 6 & 5 & 5 & 16 & Good \\
\hline 6 & 4 & 6 & & \\
\hline 5 & 6 & 5 & & \\
\hline 5 & 5 & 5 & 15 & Fair \\
\hline 6 & 4 & 5 & & \\
\hline 5 & 4 & 6 & & \\
\hline 6 & 5 & 4 & & \\
\hline 4 & 6 & 5 & & \\
\hline 5 & 4 & 5 & 14 & Poor \\
\hline 5 & 5 & 4 & & \\
\hline 4 & 5 & 5 & & \\
\hline 6 & 2 & 5 & 13 & \\
\hline & & & Arthrodesis & \\
\hline 4 & 4 & 4 & $(12,11,10)$ & \\
\hline 5 & 3 & 4 & & \\
\hline \multicolumn{4}{|c|}{ Place here the post-surgery results if no clinical improvement or aggregation $\leq 9$} & $\mathrm{Bad}$ \\
\hline
\end{tabular}



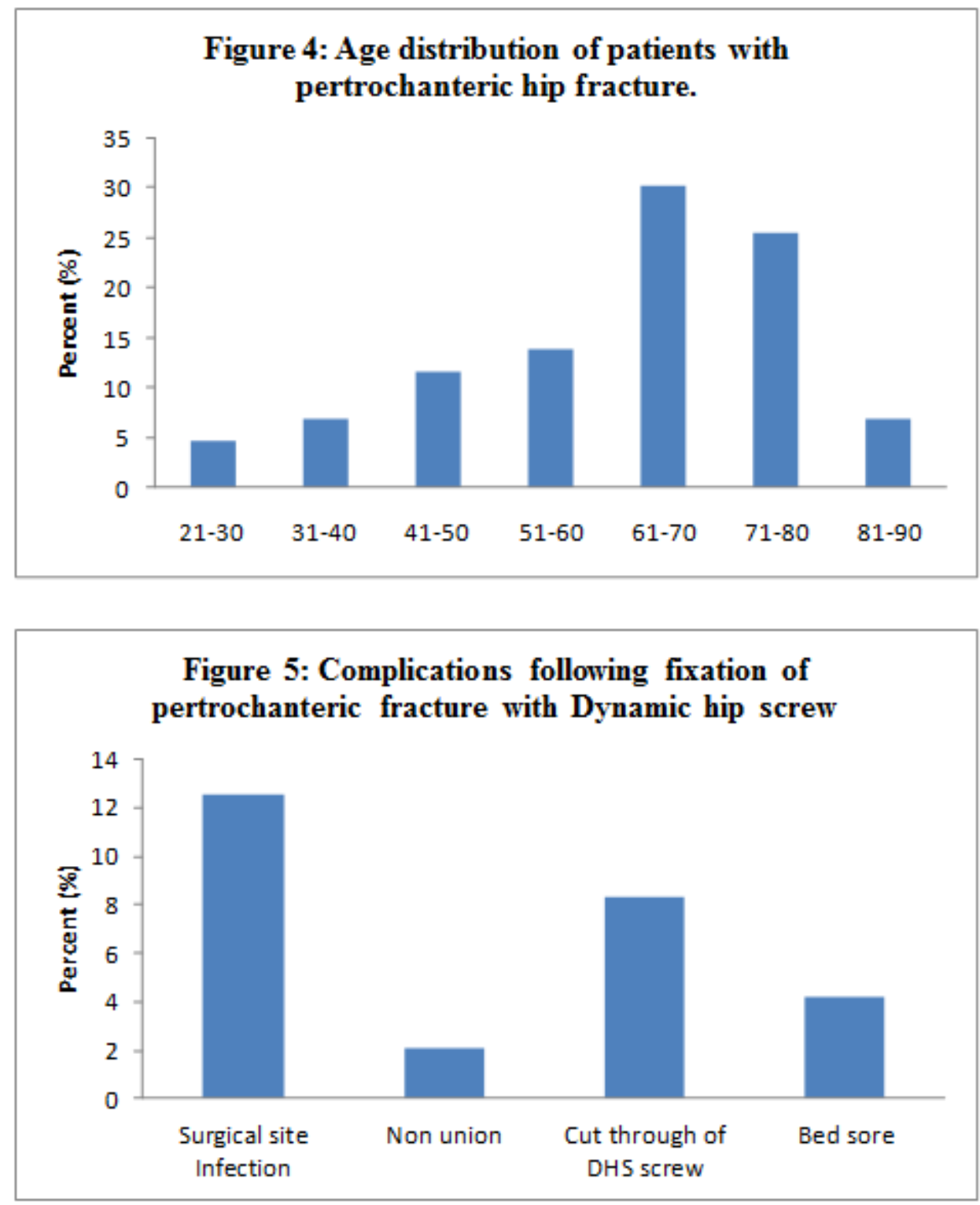

Figure 6: Post operative hip functional score

following treatment with dynamic hip screw.

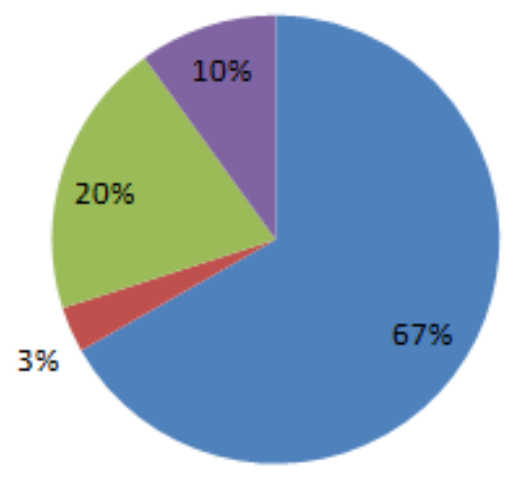

Excellent (18)

चvery good (17)

II Good (15\&16)

n Fair (14\&15) 


\section{Discussion}

Pertrochanteric (Extra capsular) fractures of the proximal femur form a major share of fractures in the elderly patients. Osteoporosis, co-morbidities, increased incidence of trivial trauma increases the incidence and complicates the treatment of these factures. The goal of the treatment is stable fixation, which allows early mobilization and restoration of function [5].

There was a predominance of the male gender in this study with a male to female ratio of $1.4: 1$ with the male gender prevailing by $58.3 \%$. This agrees with local studies [20,21] but at variance with western studies which women are twice at risk due to post menopausal osteoporosis and longer lifespan $[18,19]$ The age range was 28 to 90 years with mean age of $63.8 \pm 15$ years is in keeping with results obtained in local studies [ 20,21] ,however, the mean age of $72-77$ years reported in western studies $[22,23]$ reflect the higher life expectancy of their population. The predominant mechanism of injury was trivial falls in $26(54.2 \%)$ patients. This is in keeping with previous studies [23-25]. Seven (14.6\%) patients were involved in motorcycle accident reflecting the recklessness of commercial motorcyclist as a common etiology for trauma in developing countries [20, 21]. Majority $(57.7 \%)$ of the women were involved in low energy injury- trivial falls which reflects the higher incidence of osteoporosis in women ${ }^{18,19}$ while more men $(84.6 \%$ and $85.7 \%)$ were involved in high energy injury - motor cycle accident and vehicular accident respectively reflecting the adventurous nature of the male gender.

There was delay in presentation as only $4(11.4 \%)$ patients presented within 48 hours of injury. Majority $(71.4 \%)$ of the patients presented above 3 weeks of injury. This late presentation and probable worsening of fracture displacement from repeated manipulation by traditional healers and bone setters who dabble into fracture management unabated and without regulation in developing countries [20, 21] This may presents with difficulty in achieving closed reduction during the conduct of surgery. Minimal exposure of the fracture site may be required in this case where fibrous /soft tissue interposition is cleared and fracture ends are freshened in order to achieve adequate reduction.

The commonest complication encountered was surgical site infection in $6(12.5 \%)$ patients. This was superficial surgical site infection and was treated by removal of alternate stitches, daily wound dressing and antibiotics therapy according to sensitivity pattern. Some local studies reported crude infection rate of (4.8 $20 \%)[20,21]$ and international studies $(0-4.7 \%)[25,29]$. Rate of infection is kept low by observing aseptic techniques, routine use of prophylactic antibiotic, general measures for keeping operation room clean and keeping such patients in the ward away from the infected patients.

Mechanical failure of the DHS due to lag screw cut- through was encountered in $4(8.3 \%)$ patients. This necessitated revision surgery in $3(6.2 \%)$ patients and conversion to hemiarthroplasty in $1(2.1 \%)$ patient. This is comparable with previous studies which reported lag screw cut- through as the commonest mechanical failure $(6.8-13 \%)$ of fixation with the sliding hip screw system ${ }^{9-13}$. Baumgaertner et al [15-17] described the Tip apex distance (TAD) as a useful intraoperative indicator for deep and central placement of the lag screw in the femoral head and the most important factor in predicting lag-screw cut- through with the DHS. The ideal position of the lag screw in both planes of the femoral head is within $10 \mathrm{~mm}$ of the subchondral bone and a tip apex distance of $<25 \mathrm{~mm}$ has been shown to be generally predictive of successful result ,however most surgeons may opt for a tip-to-apex distance of $<20 \mathrm{~mm}$ [26]. The best lag-screw positions is the middle/middle position, or inferior/middle position [27, 28] as shown in Fig.2.

A significantly high incidence of lag-screw cut-through is associated with unstable fracture patterns such as reverse oblique fractures, trans trochanteric fractures, fractures with large posteromedial fragment implying loss of calcar buttress and fractures with subtrochanteric extension. These fractures should be treated with intramedullary nail because of more favorable biomechanical properties compared with a sliding hip screw. An intramedullary nail is located closer to the center of gravity than a sliding hip screw, and therefore the liver arm on the femoral fixation is shorter. Intramedullary nails can reliably resist the relatively high forces across the medial calcar that are typically borne by the implant in an unstable fracture. The intramedullary position of the implant also prevents shaft medialization, which is a common complication associated with the transtrochanteric and reverse oblique fracture patterns. Recognizing the unstable patterns preoperatively and choosing to use an intramedullary nail may decrease the risk of fixation failures. Similarly, fractures that involve the lateral wall of the femur are by definition, either reverse oblique or transtrochanteric fractures do not have any lateral osseous buttress and therefore, if a sliding hipscrew is used, medial translation of the femoral shaft and lateralization of the proximal femoral fragment can occur as depicted in Fig.3. This results in deformity, non-union and screw cut out. Haldukewych et al [29] reported a 56\% failure rate when DHS was used in reverse oblique fractures of the proximal femur. Locking plates and $95^{\circ}$ condylar blade plates which may function as prosthetic lateral cortices or intramedullary nail may suffice in this case.

High incidence of lag screw cut through is frequently encountered in elderly patients with osteoporosis who usually are not able to walk without weight bearing which often result in failure of the DHS system. Careful patient selection is advocated and alternative treatment modality with primary hemiarthroplasty for 
severe osteoporosis may be considered in such situations as immediate full weight bearing regardless of bone quality is achieved after primary cemented arthroplasty with satisfactory functional outcome.

Complications of non-union may be ameliorated by adequate fracture reduction to ensure broad surface contact. Reduction is considered good if the cortical congruence at the calcar region was restored, and if the displacement between the fragments did not exceed $2 \mathrm{~mm}$ in any projection. All the threads of the lag screw must be well beyond the fracture line to ensure adequate compression of the fracture site when the compression screw is applied as well as stable immobilization until the fracture unites. Pressure sore was observed in 2 (4.2\%) patient. This was Shea grade 1 which healed uneventfully following daily dressing and mobilization of the patients. Early graded mobilization is advocated to forestall this complication.

Early post-operative mortality was $2.1 \%$. Previous studies [22, 23,30] showed one year post-operative mortality rate of $12 \%$ to $37 \%$ in elderly patients with pertrochanteric fractures. Mortality rate depends on age of the patients and systemic comorbidities [23, 24, 31]. Follow up time of patients was poor as patients default frequently after a few visits. Seven patients (14.5\%) were initially lost to follow up and never seen in surgical outpatient clinic following discharge from the hospital. At 6 months follow up, only 38 (79.2\%) patients were seen. This had dropped to $9(18.8 \%)$ patients at 1year and only $6(18.5 \%)$ patients were seen after 1 year. This inconsistent follow up and difficulty in contacting our patients makes it challenging to accurately ascertain the postoperative mortality pattern as some deaths had probably occurred at home after the last consultation.

Post-operative hip functional status of done according to Postel and Merle d Aubigne scoring system at $4-6$ months revealed that majority $(90.0 \%)$ of the surviving patients had satisfactory hip functional score $\{$ Excellent $(66.9 \%)$, Very Good(3.3\%) and Good(20.0\%)\} as illustrated in Fig. 6. This suggest that the use of DHS is supported by biomechanical properties which improve the healing of fractures and the relatively well restored anatomy favors restoration of function and allow patients to return to their previous level of activity.

\section{CONCLUSION}

The results from this study suggest that pertrochanteric fracture is relatively common in our environment with higher incidence seen in elderly patients above 60years. Functional outcome of fixation was satisfactory as majority of patients returned to their previous level of activity. The commonest mechanical failure of fixation encountered in the sliding hip screw system was cut-through of the implant from the femoral head. Careful patient selection, proper training of surgeons and attention to detail is vital and may minimize complications in the treatment of pertrochanteric hip fractures with dynamic hip screw.

\section{Acknowledgement}

We wish to appreciate the management of NKST rehabilitation hospital Mkar, Benue state-Nigeria for their substantial support towards data acquisition.

\section{REFERENCES}

[1] Hoffmann R, Hass NP. Trochanteric fractures; Principles of Management, Acta Orthop Belg, 66(1), 2000, 34-39.

[2] Finsen V, Benum P. Trochanteric fractures, Clin Orthop Relat Res, 218(1), 1987, 104-110.

[3] Finsen V, Johnsen LG, Trano G, Hansen B, Sneve KS. Management of pertrochanteric fractures. Clin Orthop Relat Res, 419(1), 2004, 173-180.

[4] Kyle RF, Gustilo RB, Premer RF, Trochanteric fractures, J Bone Joint Surg Am, 61, 1979, 216.

[5] Broos PLO, Fourneau I. Trochanteric fractures, Acta Orthop Belg, 66(1), 2000, 34-40.

[6] Rûedi TP, Murphy WM. American Society of Anesthesiologists New classification of physical status. Anesthesiology, 24, 2009, 111-118.

[7] Cleveland M, Bosworth DM, Thompson FR, Wilson HJ, Ishizuka T, A ten-year analysis of intertrochanteric fractures of the femur, J Bone Joint Surg, 41, 1959, 1399-1408.

[8] Mainds CC, Newman RJ, Implant failures in patients with proximal fractures of the femur treated with a sliding screw device, Injury, 20, 1989, 98-100.

[9] Davis TR, Sher JL, Horsman A, Simpson M, Porter BB, Checketts RG. Intertrochanteric femoral fractures: mechanical failures after internal fixation, J Bone Joint Surg Br, 72, 1990, 26-31.

[10] Kyle RF, Fractures of the proximal part of the femur, J Bone Joint Surg Am 76, 1994, 924-950.

[11] Geller JA, Saifi C, Morrison TA, Macaulay W, Tip-apex distance of intramedullary devices as a predictor of cut-out failure in the treatment of peritrochanteric elderly hip fractures. Int Orthop, 42(1), 2009, 34-40

[12] Babbister GC, Gibson AG, Ackroyed CE, Newman JH, The Fixation and prognosis of Trochanteric Fractures: A Radomised Prospective Controlled Trial, Clin Orthop Relat Res 254, 1990, 241-6.

[13] Hsueh KK, Fang CK, Chen CM, Su YP, Wu HF, Chiu FY. Risk factors in cutout of sliding hip screw in intertrochanteric fractures: An evaluation of 937 patients. Int Orthop, 34, 2010, 1273-6.

[14] Thomas AP. Dynamic hip screw that fail. Injury, 22, 1991, 45-6.

[15] Baumgaertner MR, Curtin SL, Lindskog DM, Keggi JM. The value of the tip - apex distance in predicting failure of fixation of peritroteric fractures of the hip, J Bone Joint Surg Am, 77, 1995, 1058-64.

[16] Baumgaertner M, Solberg B, Awareness of Trip - Apex Distance reduces failure of fixation of trochanteric fractures of the hip, J Bone Joint Surg [Br], 79, 1997, 969-71.

[17] Nordin S, Zulkifli O, Faisham WI. Mechanical failure of Dynamic Hip Screw (DHS) Fixation in Inertrochanteric fracture of the femur. Med J Malaysia 2001; 56: 12-7. 
[18] Lauritzen JB. Hip fractures: Epidemiology, risk factors, falls, energy absorption, hip protectors, and prevention, Dan Med Bull, 44(2), 1997, 155-168.

[19] Lauritzen JB, Hip fractures: Epidemiology, risk factors, falls, energy absorption, hip protectors, and prevention, 44(2), 1987, 155168

[20] Onche II, Yinusa W.Femoral neck fractures: A prosprctive assessment of the pattern, care and outcome in an orthopaedic centre, Nigeria Journal of Orthopaedics and Trauma, 11, 2004, 42-41.

[21] Aristote H, Moevi A, Michel L, Soumaila M, Repestre Z, Jijoho P, Treatment of Femoral Fracture by Moore Prothesis in Cotonou, Nigerian Journal of Orthopaedics and Trauma, 9(1), 2010, 5-7.

[22] Kannus P, Parkkari J, Sievanen H, Heinonen A, Vouri I, Jarvinen M. Epidemology of hip fractures" Bone , 1, 1996, 57-63.

[23] Baumgaertner MR, Higgins TF. Femoral Neck Fractures. Rockwood \& Green's Fractures in Adults(2002) 1579-1586.

[24] Torio CM, Andrews RM. National Inpatient Hospital Costs: The Most Expensive Conditions. Healthcare Research, 42(1), 2013, 74-79

[25] Cumming RG, Nevitt MC, Cummings SR.Epidemiology of Hip Fractures, J Epidemiology review 19(2), 1997, $244-257$.

[26] Pervez H, Parker MJ, Vowler S, Prediction of fixation failure after sliding hip screw fixation. Injury, 35, 2004, 994-998.

[27] Wu CC, Shih CH, Lee MY. Biomechanical analysis of location of lag screw of a dynamic hip screw in treatment of unstable intertrochanteric fracture, J Trauma, 41, 1996, 699-702.

[28] Kuang KH, Chi F, Risk factor in cutout of sliding hip screw in Intertrochanteric fractures: an evaluation of 937 patients, Int Orth.J, 34(8), 2010, $1273-1276$.

[29] Haldukewych GJ,Isreal TA, Berry DJ. Reverse obliquity fractures of the intertrochanteric region of the femur, J Bone Joint surg Am, 83, 2001, 643-50

[30] D’ Arcy J, Devas M. Treatment of fractures of femoral neck by replacement with Thompson Prosthesis, J Bone Joint Surg Br, 58, $1976,279-86$.

[31] Rubenstein LZ, Josephson KR. The Epidemiology of Falls and Syncope. J Geriatrics Medicine, 18, 2002, 141-150. 